\title{
CRESCIMENTO DE MUDAS DE GRAVIOLEIRA (Anonna muricata L.) EM SUBSTRATO COM SUPERFOSFATO SIMPLES E VERMICOMPOSTO ${ }^{1}$
}

\author{
CARLOS ALBERTO SPAGGIARI SOUZA²; FERNANDO LUIZ DE OLIVEIRA CORRÊA ${ }^{3}$; VANDER MENDONÇA, \\ JANICE GUEDES DE CARVALHO's
}

\begin{abstract}
RESUMO - Objetivando avaliar o efeito de diferentes doses de superfosfato simples e vermicomposto no crescimento de mudas de gravioleira (Anonna muricata L.), conduziu-se um experimento no Setor de Fruticultura da Universidade Federal de Lavras. Foram testadas, num Latossolo, quatro doses de superfosfato simples $(0,0 ; 2,5 ; 5,0$ e $10,0 \mathrm{~kg})$ e quatro doses de vermicomposto $(0 ; 10 ; 20$ e $40 \%) \mathrm{m}^{-3}$ de substrato. O delineamento experimental utilizado foi blocos ao acaso em esquema fatorial 4 x 4, com 4 repetições. Foram realizadas as seguintes determinações: altura de plantas $(\mathrm{cm})$, diâmetro do caule $(\mathrm{cm})$, número de folha/planta, área foliar $\left(\mathrm{cm}^{2} \cdot\right.$ planta $\left.{ }^{-1}\right)$, matéria seca de folha, do caule e de raiz $\left(\mathrm{g} \cdot \mathrm{planta} \mathrm{f}^{-1}\right)$. Os resultados demonstraram que a aplicação de superfosfato simples na dose de $5 \mathrm{~kg}$ e $40 \%$ de vermicomposto por $\mathrm{m}^{3}$ de substrato proporcionaram a obtenção de mudas de gravioleira mais vigorosas.
\end{abstract}

Termos para indexação: graviola, propagação, adubação orgânica e adubação fosfatada

\section{GROWING OF SOURSUP SEEDLINGS (Anonna muricata L.) IN SUBSTRATE WITH SIMPLE SUPERPHOSPHATE AND EARTHWORM}

\begin{abstract}
An experiment was conducted at the fruits sector of the Lavras Federal University -UFLA in order to evaluate the effect of different amounts of earthworm and simple superphosphate in the growing and nutrition of soursup seedlings (Anoma muricata L.). Four dosages of simple superphosphate $\left(0,0 ; 2,5 ; 5,0\right.$ and $10,0 \mathrm{~kg} \mathrm{~m}^{-3}$ of substratum) and four dosages of earthworm $(0,0 \% ; 10,0 \% ; 20,0 \%$ and $40,0 \%$ of volume $)$ were tested at Latosol. The experimental design was randomized block in a two factors arrangement $(4 \mathrm{x} 4)$ with 4 replicates. The plants height (cm); stem diameter $(\mathrm{cm})$; matter of the aerial part and roots (g per plant); number of leaves per plant and leaves area $\left(\mathrm{cm}^{2}\right.$.plant ${ }^{-1}$ ) were evaluated. The results showed that the use of simple superphosphate at $5 \mathrm{~kg} \mathrm{~m}^{-3}$ with $40,0 \%$ of earthworm provided soursup seedlings with superior quality compared to the others.

Index Terms: Soursup, propagation, organic fertilization, phosphorus fertilization
\end{abstract}

\section{INTRODUÇÃO}

A gravioleira (Anonna muricata L.) está presente em quase todos os países da América tropical. Embora não seja nativa do Brasil, é cultivada, praticamente, em todos os estados do norte e nordeste.

A propagação da gravioleira passa pela produção de mudas que é um dos meios para a exploração técnica e comercial dessa espécie. Tratase de uma cultura perene e os erros cometidos no processo de produção de mudas, com toda certeza poderão proporcionar conseqüências danosas por todo o período de exploração da cultura.

Para a obtenção de mudas de boa qualidade, faz-se necessário a utilização de substratos, os quais devem apresentar propriedades físicas e químicas adequadas e fornecer os nutrientes necessários para o desenvolvimento da planta. Além disso, a qualidade do substrato depende, primordialmente, das proporções e dos materiais que compõem a mistura ( Silva et al., 2001).

O substrato exerce influência significativa sobre a arquitetura do sistema radicular, no estado nutricional das plantas (Spurr \& Barnes, 1973) e no movimento da água no sistema solo-planta-atmosfera (Orlander \& Due, 1986). Os substratos são escolhidos em função da disponibilidade e de suas propriedades físicas e, muitas vezes, substratos com baixos teores de nutrientes são usados, sendo necessária a adição de fertilizantes (Souza, 1983). Bons substratos apresentam boas características de firmeza, volume razoavelmente constante quando secos ou úmidos, capacidade de retenção de água, porosidade para facilitar a drenagem e permitir a aeração, boa sanidade, baixo nível de salinidade e boa disponibilidade de nutrientes (Hartmann \& Kester, 1975; Blanc, 1981).

Na produção de mudas de fruteiras, vários substratos têm sido utilizados tais como: esterco de curral associado com carvão vegetal, solo e areia (Mendonça et al., 2003); casca de arroz carbonizada (Souza, 2001); bagaço de cana-de-açúcar (Toledo et al., 1997); esterco de ani- mais (Sediyama et al., 2000), isolados ou associados a fontes e doses de fertilizantes minerais (Vichiato et al., 1998; Brasil et al., 1999). No entanto, na produção de mudas de gravioleira, trabalhos utilizando substratos são escassos, restringindo-se aos de Barbosa (1990) e Pinto \& Silva (1994).

$\mathrm{Na}$ formação de mudas, um suprimento adequado em fósforo proporciona respostas significativas tanto no crescimento do sistema radicular como da parte aérea. Desta forma, um substrato deficiente em $\mathrm{P}$ poderá ocasionar um crescimento reduzido ou menor das raízes e da parte aérea, sendo necessária a fertilização com adubos fosfatados (Yeager \& Wright, 1984).

Por outro lado, vários trabalhos envolvendo o uso de diferentes fontes de fertilizantes fosfatados ressaltam sua importância na fase de formação das mudas de diferentes espécies frutíferas: maracujá (Peixoto, 1986), mamão (Rocha, 1987), citros (Souto, 1993) e banana (Menezes, 1997). Neste sentido, objetivou-se neste trabalho avaliar o crescimento de mudas de gravioleira em substrato, utilizando doses de superfosfato simples e vermicomposto.

\section{MATERIALEMÉTODOS}

O experimento foi conduzido no Setor de Fruticultura do Departamento de Agricultura da Universidade Federal de Lavras (UFLA), Minas Gerais. As mudas utilizadas nesta pesquisa foram obtidas de sementes oriundas de plantas da variedade Lisa da Estação Experimental Filogônio Peixoto, em Linhares (ES), pertencente à Comissão Executiva do Plano da Lavoura Cacaueira - CEPLAC.

Como substrato, utilizou-se solo classificado como Latossolo Vermelho distroférrico, coletado na camada de $0-20 \mathrm{~cm}$ de profundidade, no campus da UFLA, cujos resultados da análise química encontram-se na Tabela 1.

\footnotetext{
'(Trabalho 101/2002). Recebido: 15/08/2002. Aceito para publicação: 11/09/2003.

${ }^{2}$ Eng. Agrônomo, Dr. Prof. Visitante do Departamento de Agricultura-UFLA, Cx. Postal 137, CEP 37200-000, Lavras-MG, Fone (0xx35)3821-2851, E-mail casouza@ufla.br.

${ }^{3}$ Eng. Agrônomo, M. Sc. Doutorando em Agronomia/Fitotecnia -UFLA - Pesquisador CEPLAC/ESTEX-OP, Ouro Preto do Oeste- RO, Cx.Postal. 11, Fone (0xx35) 3821-1929, E-mail floc@ufla.br.

${ }^{4}$ Eng. Agrônomo M.Sc. Doutorando em Agronomia/Fitotecnia-UFLA, Lavras-MG CEP 37200-000, fone (35)3822-5210, vander@ufla.br.

${ }_{5}^{5}$ Eng. Agrônoma Dra. Prof ${ }^{a}$. Titular , Dep ${ }^{\circ}$. de Solos - UFLA, Lavras-MG, CEP 37200-000, fone: (35)3829-1269, janicegc@ufla.br.
} 
TABELA1 -Análise química do solo utilizado como substrato no experimento de gravioleira. Lavras-MG, 1997.

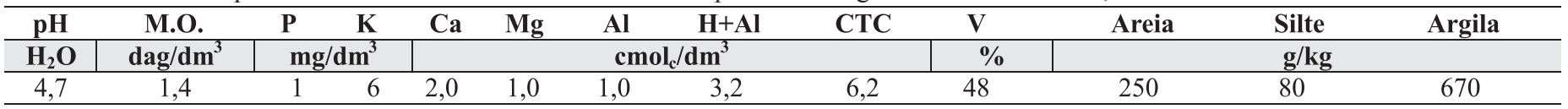

As sementes foram colocadas para germinar em bandejas com substrato de areia lavada e após 20 dias da germinação, realizou-se o transplantio para sacos plásticos $(14 \times 28 \mathrm{~cm})$, com capacidade para $2,0 \mathrm{~kg}$ de solo, furados lateralmente. Foi transplantada uma única muda por recipiente, conforme a recomendação de Pinto \& Silva (1994).

A adubação do substrato realizou-se uma semana antes do transplantio, misturando ao substrato o vermicomposto nas quantidades de $0 ; 10 ; 20$ e $40 \%$ do volume do substrato e o superfosfato simples (180 g de $\mathrm{P}_{2} \mathrm{O}_{5} \mathrm{~kg}^{-1}$, solúvel em água) nas doses de $0 ; 2,5 ; 5 ; \mathrm{e} 10 \mathrm{~kg}$ por metro cúbico de substrato.

O experimento foi conduzido em viveiro coberto com sombrite $50 \%$, por um período de 7 meses após o transplantio. Os tratos culturais utilizados foram a irrigação, o controle de pragas e doenças e a monda das plantas daninhas. A adubação de cobertura, via foliar, foi realizada mensalmente durante 5 meses, iniciando após um mês do transplantio com aplicação de nitrogênio, utilizando as seguintes fontes alternadamente: uréia $(0,2 \%)$ e sulfato de amônio $(0,4 \%)$.

$\mathrm{O}$ delineamento experimental utilizado foi em blocos casualizados, em esquema fatorial $4 \times 4$. Os tratamentos foram constituídos pela combinação de 4 doses de superfosfato simples $(0 ; 2,5 ; 5$ e 10 $\mathrm{kg}$ por metro cúbico de substrato ) e 4 doses de vermicomposto ( $0 ; 10$; 20 e $40 \%$ do volume do substrato) com 4 repetições. Cada parcela foi constituída de 3 mudas ( 3 recipientes com 1 muda cada). As combinações dos tratamentos encontram-se descritas na Tabela 2.

TABELA2- Tratamentos utilizados no experimento. Lavras-MG, 1997.

\begin{tabular}{lcc}
\hline & \multicolumn{2}{c}{ Discriminação } \\
\cline { 2 - 3 } Tratamento s & $\begin{array}{c}\text { superfosfato simples } \\
\left(\mathrm{kg} / \mathrm{m}^{3} \text { de substrato }\right)\end{array}$ & $\begin{array}{c}\text { Vermicomposto } \\
\left(\% / \mathrm{m}^{3}\right.\end{array}$ \\
& 0,0 & 0 \\
$\mathrm{~T}_{1}$ & 0,0 & 10 \\
$\mathrm{~T}_{2}$ & 0,0 & 20 \\
$\mathrm{~T}_{3}$ & 0,0 & 40 \\
$\mathrm{~T}_{4}$ & 2,5 & 0 \\
$\mathrm{~T}_{5}$ & 2,5 & 10 \\
$\mathrm{~T}_{6}$ & 2,5 & 20 \\
$\mathrm{~T}_{7}$ & 2,5 & 40 \\
$\mathrm{~T}_{8}$ & 5,0 & 0 \\
$\mathrm{~T}_{9}$ & 5,0 & 10 \\
$\mathrm{~T}_{10}$ & 5,0 & 20 \\
$\mathrm{~T}_{11}$ & 5,0 & 40 \\
$\mathrm{~T}_{12}$ & 10,0 & 0 \\
$\mathrm{~T}_{13}$ & 10,0 & 10 \\
$\mathrm{~T}_{14}$ & 10,0 & 20 \\
$\mathrm{~T}_{15}$ & 40 \\
$\mathrm{~T}_{16}$ & 10,0 & \\
\hline
\end{tabular}

As variáveis avaliadas, aos 7 meses após o transplantio, foram: altura de planta $(\mathrm{cm})$, medida a partir do colo da muda até a gema apical; diâmetro do caule $(\mathrm{cm})$ a $5 \mathrm{~cm}$ do solo; número de folha/planta e, em seguida, as mudas foram cortadas rente ao solo, separando a raiz, caule e folha, lavadas em água de torneira e água destilada, e as partes acondicionadas, separadamente, em saco de papel. As folhas, antes da secagem, foram usadas para determinar a área foliar $\left(\mathrm{cm}^{2}\right.$.planta $\left.{ }^{-1}\right)$, utilizandose integrador de área foliar. Posteriormente as partes foram secadas em estufa com circulação forçada de ar à temperatura de $\pm 65^{\circ} \mathrm{C}$, até atingir peso constante para obtenção da matéria seca.

Os resultados foram submetidos à análise de variância e as médias dos dados comparadas pelo teste de Tukey a $5 \%$ de probabilidade, sendo seguidas as recomendações de Gomes (2000).

\section{RESULTADOS E DISCUSSÃO}

Pela análise de variância observou-se efeitos significativos da interação das doses de superfosfato simples e do vermicomposto para as variáveis número de folhas, diâmetro do caule, área foliar, matéria seca do caule e da raiz. Para a altura da muda e a matéria seca da folha, houve efeito significativo apenas as doses de vermicomposto.

A altura da muda de gravioleira variou de $22,88 \mathrm{~cm}$ sem aplicação de vermicomposto até $44,35 \mathrm{~cm}$ com aplicação de $40 \%$ de vermicomposto (Figura 1). A matéria seca de folha ficou entre 4,42 g sem aplicação de vermicomposto e 12,66 g com aplicação de 40\% de vermicomposto (Figura 2). Estes resultados evidenciam que a adição de vermicomposto ao substrato de formação das mudas proporcionou um maior crescimento das mesmas, com efeito significativo a partir da dose $20 \%$ de vermicomposto, para as duas variáveis. Rego (1992), estudando o efeito da adubação orgânica (esterco bovino curtido) nas doses de $0,5,15$ e $20 \%$ do volume de substrato em mudas de gravioleira, durante quatro meses, verificou que para a altura da muda, diâmetro do colo e número de folhas a dose de $15 \%$ foi o mais eficiente. $\mathrm{Na}$ formação de mudas de laranjeira cultivar Pêra, Toledo et al. (1997), utilizando várias formulações de substrato, verificaram que a relação 30-40$30 \%$ de solo-areia-vermicomposto, foi a que apresentou efeitos significativos para altura e diâmetro do colo.

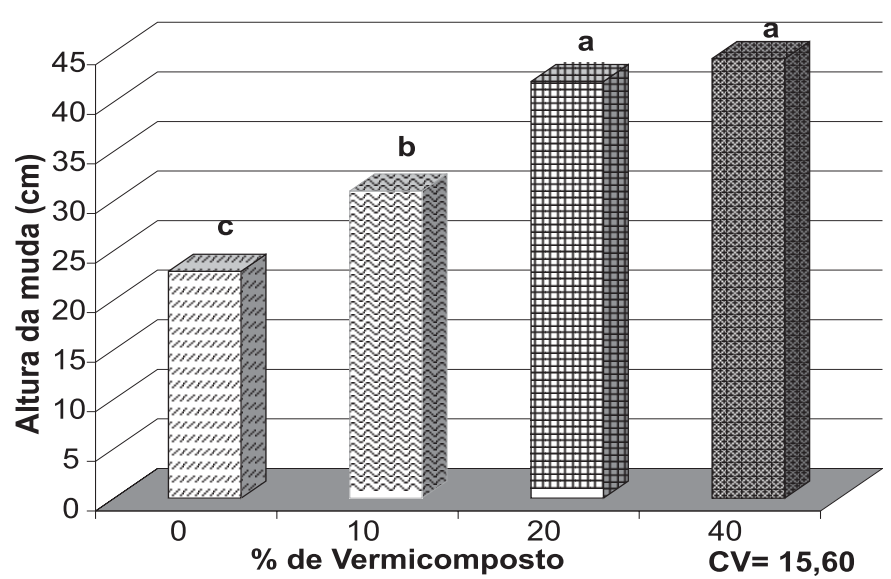

FIGURA1 - Altura da muda de gravioleira em substratos com diferentes quantidades de vermicomposto. Lavras-MG, 1997.

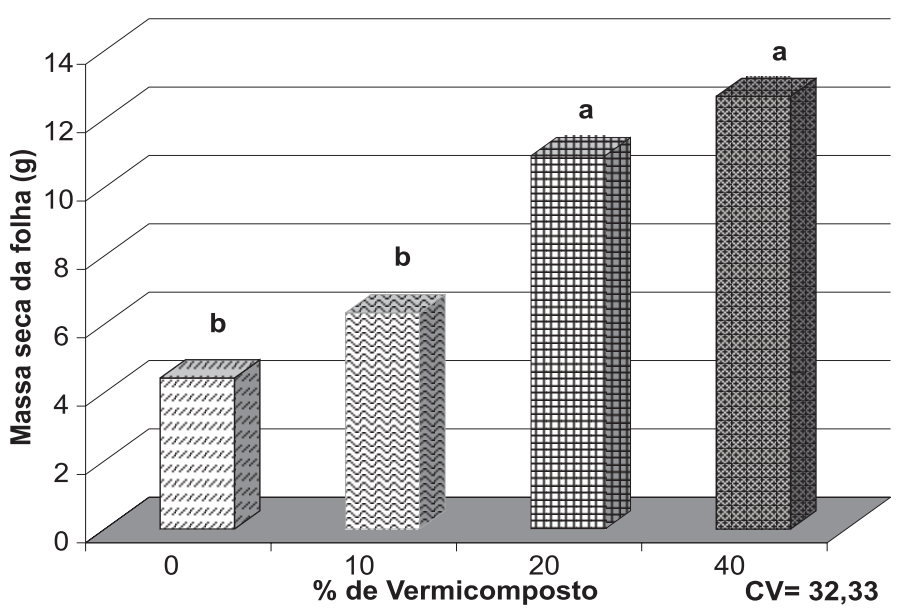

FIGURA 2 - Massa seca da folha de mudas de gravioleira em substratos com diferentes quantidades de vermicomposto. LavrasMG, 1997. 
Para a variável número de folhas nas mudas de gravioleira, a melhor resposta foi com $20 \%$ de vermicomposto e 5,0 kg de superfosfato simples por metro cúbico de substrato, apresentando em média 26,7 folhas/ planta (Figura 3). Para área foliar, a interação foi significativa para a dose 10 $\mathrm{kg}$ de superfosfato simples por metro cúbico de substrato sem a adição de vermicomposto, com área foliar de $381,38 \mathrm{~cm}^{2}$. planta $^{-1}$ (Figura 4). O diâmetro do caule das mudas de gravioleira foi maior na dose $40 \%$ de vermicomposto e $5 \mathrm{~kg}$ de superfosfato simples por metro cúbico de substrato, com valor médio de $1,02 \mathrm{~cm}$ de diâmetro. Na dose de $10 \mathrm{~kg}$ de superfosfato simples houve redução no diâmetro do caule das mudas de gravioleira, exceto para o tratamento que não recebeu vermicomposto (Figura 5).

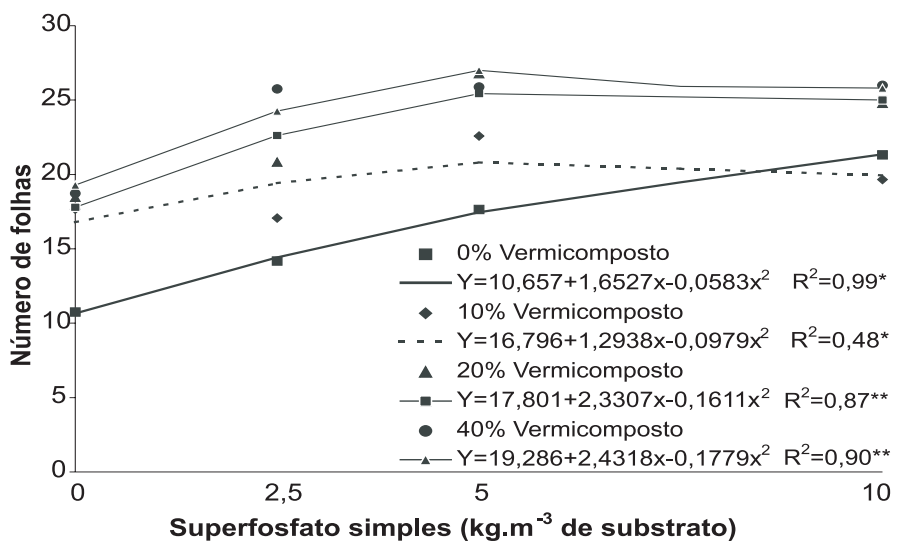

FIGURA 3 - Efeito das doses de superfosfato simples e de vermicomposto no substrato sobre o número de folhas de mudas de gravioleira. Lavras-MG, 1997.

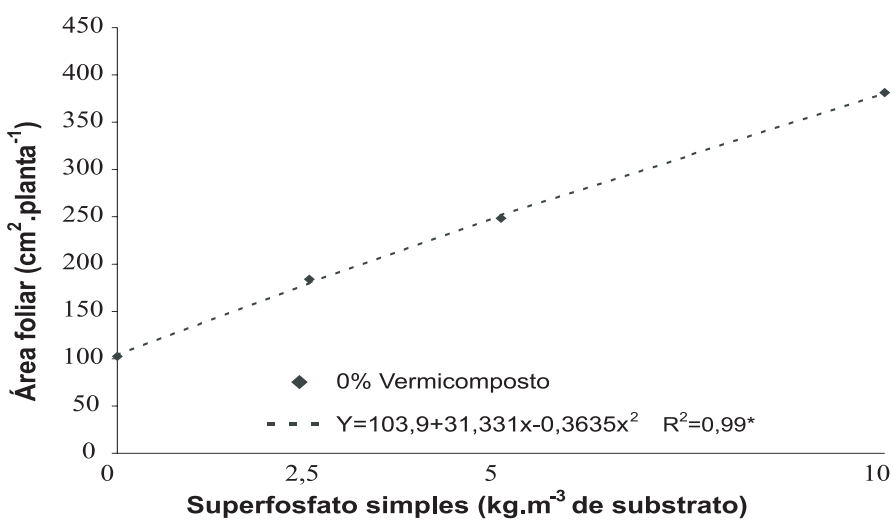

FIGURA 4- Efeito das doses de superfosfato simples e de vermicomposto no substrato sobre a área foliar de mudas de gravioleira. Lavras-MG 1997.

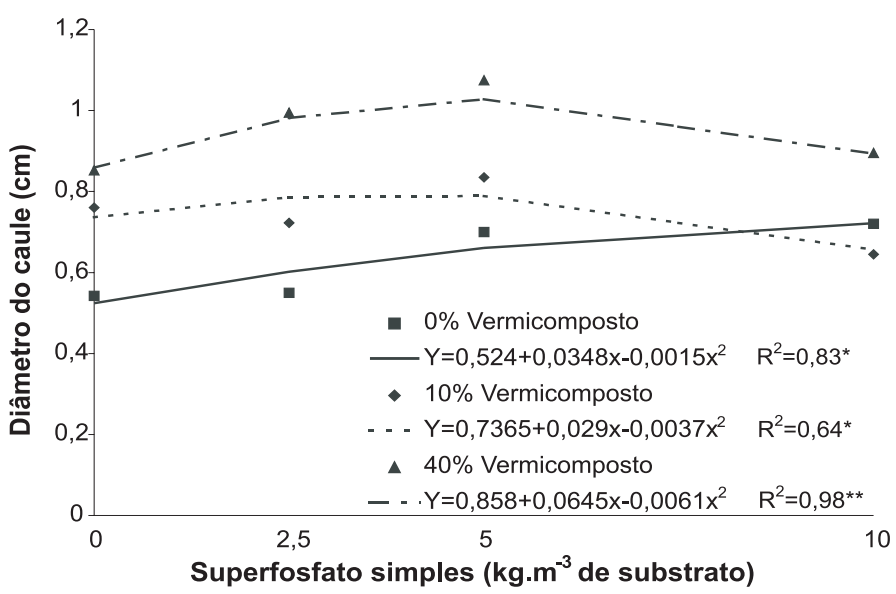

FIGURA 5- Efeito das doses de superfosfato simples e de vermicomposto no substrato sobre o diâmetro do caule de mudas de gravioleira. Lavras-MG, 1997.
A interação entre superfosfato simples e vermicomposto foi significativa para a matéria seca da raiz na combinação de $40 \%$ de vermicomposto e $2,5 \mathrm{~kg}$ de superfosfato simples por metro cúbico de substrato, com a matéria seca média de raiz de 15,12 g (Figura 6). Para a matéria seca do caule de mudas de gravioleira, a interação foi significativa nas doses de superfosfato simples combinadas com $20 \%$ e $40 \%$ de vermicomposto, com matéria seca de caule em média de $16,54 \mathrm{~g}$ na dose de $2,5 \mathrm{~kg}$ de superfosfato simples e $40 \%$ de vermicomposto (Figura 7 ). Lima et al. (2001) também encontraram resultados similares para a matéria seca da parte aérea e número de folhas em mudas de cajueiro anãoprecoce com aplicação de matéria orgânica e fertilizante mineral (uréia, superfosfato triplo e cloreto de potássio). Entretanto, Cardoso et al. (1992), utilizando doses de superfosfato simples $\left(1,25 ; 2,5\right.$ e 5,0 kg.m $\mathrm{m}^{-3} \mathrm{de}$ substrato), constataram incrementos na matéria seca da parte aérea e das raízes de mudas de cafeeiro 'Mundo Novo' e 'Catuaí' produzidas em saquinhos de polietileno. No entanto, estes mesmos autores constataram incremento na altura da mudas com a utilização do superfosfato simples, o que não foi observado nesta pesquisa com mudas de gravioleira, uma vez que apenas o vermicomposto a $40 \%$ de volume de substrato teve influência na altura das mudas.

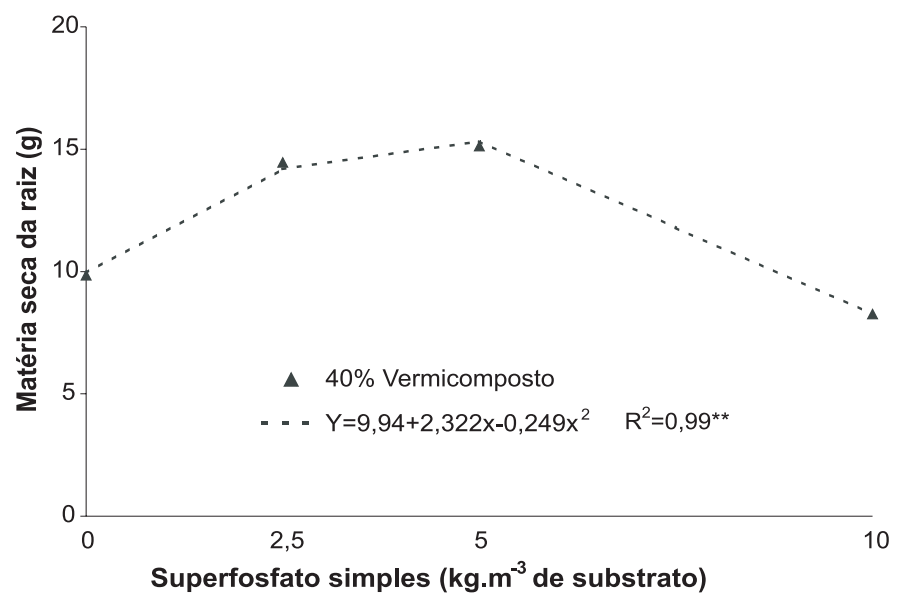

FIGURA 6- Efeito das doses de superfosfato simples e de vermicomposto no substrato sobre a matéria seca da raiz de mudas de gravioleira. Lavras-MG, 1997.

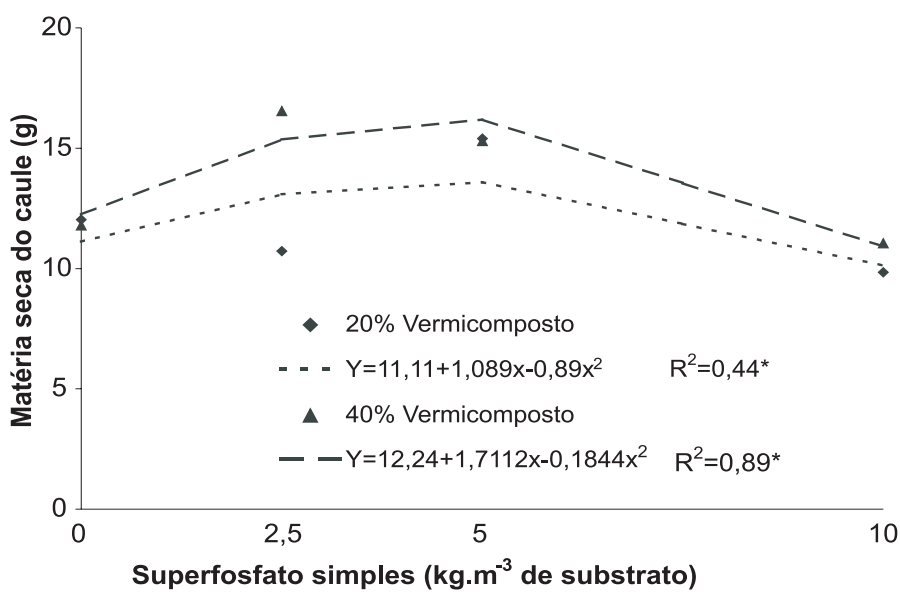

FIGURA 7 - Efeito das doses de superfosfato simples e de vermicomposto no substrato sobre a matéria seca do caule de mudas de gravioleira. Lavras-MG, 1997.

\section{CONCLUSÕES}

De acordo com os resultados obtidos e nas condições que foi desenvolvido esta pesquisa, conclui-se que:

1) A associação de vermicomposto e fertilizante superfosfato 
simples promoveu aumento no número de folhas, diâmetro do caule, na matéria seca de raízes e de caule de mudas de gravioleira.

2) A aplicação de superfosfato simples na dose de $5 \mathrm{~kg}$ por metro cúbico de substrato com $40 \%$ de vermicomposto proporcionou a obtenção de mudas de gravioleira mais vigorosas.

\section{REFERÊNCIAS BIBLIOGRÁFICAS}

BARBOSA, I. do S. Influência de diferentes fontes de matéria orgânica no desenvolvimento inicial e concentração de N P K em mudas de gravioleira (Anonna muricata L.) 1990. 89f. Monografia (Trabalho de graduação em Engenharia Agronômica) - Universidade Federal da Paraíba, Areia, 1990

BLANC, D. An outlook on substrates in France (Fertilizers, mineral nutrientes). Acta Horticulturae, The Hague, v.126, p.19-23, May 1981.

BRASIL, E. C.; SILVA, A. M. B.; MULLER, C. R.; SILVA, G. R. Efeito da adubação nitrogenada e potássica e do calcário no desenvolvimento de mudas de aceroleira. Revista Brasileira de Fruticultura, Jaboticabal-SP, v.21, n.1, p.52-56, 1999

CARDOSO, E. L; ALVARENGA, G.; CARDOSO, M. M. de; CARVALHO, J. G. de, Efeito de doses de superfosfato simples em substrato, sobre o desenvolvimento de mudas de cafeeiro (Coffea arabica L.) "Mundo Novo" e "Catuaí". Ciência e Prática, Lavras, v.16, n.1, p.35-38, 1992.

HARTMANN, H. T.; KESTER, D. E.Plant propagation: principles and practices. 3.ed. New Jersey: Prentice-Hall, 1975. 661p.

GOMES, F. P. Curso de estatística experimental. 14. ed. Piracicaba: USP, $2000.477 \mathrm{p}$.

LIMA, R. L. S de; FERNANDES, V. L. B.; OLIVEIRA, V. H. de; HERNANDEZ, F. F. F. Crescimento de mudas de cajueiro-anão precoce 'CCP-76' submetidas a adubações orgânica e mineral. Revista Brasileira de Fruticultura, Jaboticabal - SP, v. 23, n. 2, p. 391-395, 2001.

MENDONÇA, V.; ARAÚJO NETO, S. E. de; RAMOS, J. D.; PIO, R.; GONTIJO, T. C. A. Diferentes substratos e recipientes na formação de mudas de mamoeiro 'Sunrise Solo'. Revista Brasileira de Fruticultura, Jaboticabal-SP, v.25, n.1, p.127-130, abril 2003.

MENEZES, A. C. de S. G. Efeito da matéria orgânica e do superfosfato simples no crescimento e nutrição de mudas de bananeira (Musa sp) cv “Grand Naime" produzidas por cultura de tecidos. 1997.63f. Dissertação (Mestrado)- Universidade Federal de Lavras, Lavras, 1997.

ORLANDER, G.; DUE, K. Location of hydraulic resistante in the soilplant pathway in seedling of Pinus silvesrtris L. grown in peat. Canadian Jornal of Forest Research, Otawa, v.16, n.1, p.115-116, 1986.
PEIXOTO, J. R. Efeito da matéria orgânica, superfosfato simples e do cloreto de potássio na formação de mudas de maracujazeiro amarelo (Passiflora edulis Sims.) 1986. 101f. Dissertação (Mestrado)Escola Superior de Agricultura de Lavras, Lavras, 1986.

PINTO,A. C. de Q.; SILVA, E. M. da,. Graviola para exportação: aspectos técnicos da produção. Brasília: EMBRAPA-SPI, 1994, 41p.

REGO, F. A. O. Efeito da adubação orgânica no desenvolvimento da gravioleira (Anonna muricata L.) em diferentes épocas. 1992 . 79f. Monografia (Trabalho de graduação em Engenharia Agronômica) Universidade Federal da Paraíba, Areia, 1992

ROCHA, A. C. da, Efeito da matéria orgânica e do superfosfato simples na formação de mudas do mamoeiro (Carica papaya L. cv. Solo). 1987. 52f. Dissertação (Mestrado)- Escola Superior de Agricultura de Lavras, Lavras, 1987.

SEDIYAMA, M. A. N.; GARCIA, N. C.; VIDIGAL, S. M.; MATOS,A. T. de, Nutrientes em compostos orgânicos de resíduos vegetais e dejetos de suínos. Scientia Agricola, Piracicaba, v.57, n.1, p.185$189,2000$.

SILVA, R. P. da; PEIXOTO, J. R.; JUNQUEIRA, N. T. V. Influência de diversos substratos no desenvolvimento de mudas de maracujazeiro azedo (Passiflora edulis Sims f. flavicarpa DEG). Revista Brasileira de Fruticultura, Jaboticabal-SP, v.23, n.2, p.377-381, agosto 2001.

SOUTO, R. F. Métodos de aplicação e doses de superfosfato simples no limoeiro (Citrus limonia Osbeck cv. Cravo) em viveiro. 1993. $75 f$. Dissertação (Mestrado)- Escola Superior de Agricultura de Lavras, Lavras, 1993.

SOUZA, F. X. de, Materiais para a formação de substratos na produção de mudas e cultivo de plantas envasadas. Fortaleza: Embrapa Agroindústria Tropical, 2001.21 p. (Documento, 43).

SOUZA, M. de, Nutrição e adubação para produzir mudas de frutíferas. Informe Agropecuário, Belo Horizonte, v.9, n.102, p.40-43, jun. 1983.

SPURR, S. H.; BARNES, B. Y. Forest ecology. New York: the Ronald Press, $1973.571 \mathrm{p}$.

TOLEDO, A. R. M. de; GIROTTO, L. F.; SOUZA, M. de, Efeito de substratos na formação de laranjeira (Citrus cinessis (L) OSBECK cv. Pêra Rio) em vaso. Ciência e Agrotecnologia, Lavras, v.21, n.1, p. 29-34, 1997.

VICHIATO, M.; SOUZA, M. de.;AMARAL, A. M. do.; MEDEIROS, M. R. de; RIBEIRO, W. G. Desenvolvimento e nutrição mineral da tangerineira-cleópatra fertilizada com superfosfato simples e nitrato de amônio em tubetes até a repicagem. Ciência e Agrotecnologia, Lavras, v.22, n.1, p. 30-41, 1998.

YEAGER, T. H.; WRIGHT, R. D. Response of IIex crenat Thunb. Cv. Helleri to superphosphat-incorporated pine bark. Hortscience, Alexandria, v.19, n.7, p. 823-826, july 1984. 